\title{
PROYECTO DE CONSTITUCIÓN
}

\section{Enrique Chirinos Soto José Luis Sardón}

\begin{abstract}
RESUMEN
El presente documento contiene el Proyecto de Constitución que presentara al Congreso Constituyente el congresista Enrique Chirinos Soto. El mismo no tuoo cardcter de alternation. No pretendia que la mayoría se desistiese de sus iniciatioas. Tuvo y tiene el proposito de mostrar al pats lo que hubiera sido el texto constitucional de su predilección.
\end{abstract}

\begin{abstract}
This document contains the Proposed Constitution that congressman Enrique Chirinos Soto presented to the Constitutional Congress. It is not an alternative Constitution. Its aim is not to change the views of congressional majority; its purpose was and is to show what in his mind the ideal constitutional text should be.
\end{abstract}

Uno no hace o no contribuye a hacer la Constitución que quiere sino la Constitución que puede. Tal es, por cierto, mi experiencia tanto para la Constitución de 1979 cuanto para la Constitución de 1993. Hay que transigir. Hay que sacrificar unos ideales para salvar otros. La política es el compromiso entre el ideal y la realidad, entre lo deseable y lo posible. Los textos legales también suponen compromiso, máxime cuando uno es representante de minoría. La mayoría tiene, por supuesto, la sartén por el mango. Pero aún la mayoría ha de transigir ante la realidad. En definitiva, la Constitución histórica es más fuerte que la Constitución escrita.

Los constituyentes de café, que elaboran sin oposición y sin debate, su propia Constitución, a mí me divierten mucho. Son como los estrategas también de café que ganan, por ejemplo, la batalla de Waterloo que Napoleón no pudo ganar. Para echar un cuarto de espadas en tales ejercicios, José Luis Sardón y yo hemos preparado, sin oposición, el proyecto de Constitución que ahora se publica (E.Ch.S.).

\section{Preámbulo}

Los suscritos, legítimos representantes del pueblo del Perú, reunidos en Congreso Constituyente, ${ }^{\circ}$

Considerando:

Que, como dice don José de San Martín, el Perú es libre e independiente por la voluntad general de los pueblos y por la justicia de su causa que Dios defiende;

Que, como quiere Simón Bolívar, la libertad del Nuevo Mundo -al que el Perú pertenece- es la esperanza del universo;

Que, como don Francisco Javier de Luna Pizarro, entendemos el federalismo para unir lo que está desunido; y no.para desunir lo que, como felizmente ocurre entre nosotros, está unido;

Que, con don Manuel Pardo, debemos ensayar una República práctica al servicio del bien común;

Que, con don Nicolás de Piérola, proclamamos fe en nuestros padres que nos hicieron libres, legándonos el encargo de hacernos grandes; 
Que reconocemos, con Victor Andrés Belaunde, al Perú como síntesis viviente de la cultura incaica y de la cultura hispánica, y de las múltiples culturas que, sobre nuestro mismo y sagrado territorio, precedieron a ambas;

Que, con don José de la Riva Agüero y Osma, profesamos el culto de nuestros héroes como piedra de toque de todo sincero peruanismo;

Que, como quiere José Luis Bustamante y Rivero, la Constitución es un contrato entre la Nación y el Estado; y que esa relación contractual debe discurrir dentro de los luminosos cauces de la juridicidad y el Estado de Derecho;

Que, en el Cuzco, capital histórica del Perú, como exclama Raúl Porras, asistimos a la presencia mágica del sol y el milagro cotidiano. de la luz;

Que, con Víctor Raúl Haya de la Torre, entendemos la necesidad de crear riqueza para el que no la tiene sin quitarla al que la tiene;

Que, con Jorge Basadre, concebimos al Perú como una continuidad en el tiempo y una totalidad en el espacio;

Yque nos inspiran las sombras ilustres, entre muchas otras, de Pachacútec; del Inca Garcilaso de la Vega; de Rosa de Lima y de San Martín de Porres; del Conde de Superunda; de José Gabriel Condorcanqui, Túpac Amaru, y de Mateo Pumacahua; de José Olaya; de José Faustino Sánchez Carrión; de Ramón Castilla; de Francisco García Calderón; de José Gálvez; de Andrés Avelino Cáceres; de Miguel Grau; de Francisco Bolognesi; de José Abelardo Quiñones; de Alipio Ponce; de Antonio Miró Quesada de la Guerra; de María Elena Moyano y de todos los que nos han precedido, sobre este suelo, en la difícil y gloriosa condición de ser peruanos, desde Tumbes hasta Tacna, desde el mar hasta la selva.

Así, invocando el nombre de Dios y renovando nuestra fe en una Patria justa, libre, soberana, cristiana, solidaria y democrática, firme y feliz por la unión, consciente de su historia; $y$, a la vez, optimista en su destino y en su desarrollo, en la que el Estado sea garante de la iniciativa privada, y ésta la herramienta para el bienestar del mayor número, hemos venido en aprobar y aprobamos la siguiente:
De los Derechos Fundamentales

Artículo 1. Superioridad de los derechos del hombre

El hombre tiene derechos anteriores y superiores al Estado. Respetarlos y protegerlos es obligación de todos.

\section{Artículo 2. Derechos del hombre}

Los derechos del hombre derivan de su dignidad como persona. Entre tales derechos, están los siguientes:

1. El derecho a la vida y la integridad.

2. A la libertad. Estederecho incluye los derechos a la libertad de conciencia y de expresión.

3. A la igualdad ante la ley. Nadie puede ser discriminado por razón alguna.

4. Al honor, a la buena reputación, la intimidad y la voz e imagen propias. Estos derechos incluyen los derechos a la inviolabilidad de la correspondencia y de las comunicaciones, así como al secreto de los papeles privados.

5. A la propiedad privada y a la herencia, así como el derecho a contratar con fines lícitos.

6. A la nacionalidad. Nadie puede ser despojado de la suya. $Y$

7. A la búsqueda de la felicidad. Todos tienen derecho al libre desenvolvimiento de su personalidad, siempre que no perturben ni atropellen los derechos de otro ni atenten contra el orden público ni las buenas costumbres.

\section{Artículo 3. Seguridad jurídica}

El hombre tiene derecho a la seguridad jurídica. Por tanto:

1. Nadie está obligado a hacer lo que la ley no manda, ni impedido de hacer lo que ella no prohíbe.

2. Están abolidas la esclavitud, la servidumbre y la trata en cualquiera de sus formas.

3. No hay prisión por deudas.

4. Nadie será procesado ni condenado por acto u omisión que al tiempo de cometerse no esté previamente calificado en la ley, de 
manera expresa e inequívoca, como infracción punible, ni sancionado con pena no prevista en la ley.

5. No hay delito de opinión.

6. Todo hombre es considerado inocente mientras no se declare judicialmente su responsabilidad.

7. Nadie puede ser detenido sino por mandato escrito y motivado del juez o de la autoridad competente, salvo flagrante delito. El detenido debe ser puesto, dentro de setenta y dos horas o en el término de la distancia, a disposición del juez que corresponde.

Se exceptúan de este precepto los casos de terrorismo, espionaje y tráfico ilícito de drogas, en los que las autoridades policiales pueden efectuar la detención preventiva de los presuntos implicados por un término hasta de quince días, con cargo de dar cuenta al juez.

Toda persona será informada, inmediatamente y por escrito, de la causa o razones de su detención. Tiene derecho a ser asesorada por un defensor de su elección desde que es citada o detenida por la autoridad.

8. Nadie puede ser incomunicado, salvo en caso indispensable para el esclarecimiento de un delito, en la forma y por el tiempo previstos por la ley. La autoridad está obligada a señalar, sin dilación y por escrito, el lugar donde se halla la persona detenida. $Y$

9. Nadie puede ser víctima de violencia física ni psicológica, ni sometido a tortura o tratos inhumanos o humillantes. Cualquiera puede pedir de inmediato el examen médico de la persona agraviada o imposibilitada de recurrir por sí misma a la autoridad. Las declaraciones obtenidas por la violencia carecen de valor.

\section{Artículo 4. Garantías constitucionales}

Son garantías constitucionales:

1. La inviolabilidad del domicilio. Nadie puede ingresar en él sin autorización de quien lo habita o sin mandato judicial, salvo los casos de flagrante delito o peligro inminente de su perpetración o por motivo de sanidad establecido por la ley.
2. La libre elección del lugar de residencia, el libre tránsito por el territorio nacional, incluyendo los derechos a salir de él y entrar en él, salvo limitaciones por razón de sanidad. Nadie puede ser expatriado ni separado del lugar de su residencia sino por mandato judicial o por aplicación de la ley de extranjería. $Y$

3. Las reuniones pacíficas sin armas. Las reuniones en locales privados o abiertos al público no requieren aviso previo. Las que se convocan en plazas y vías públicas exigen anuncio anticipado a la autoridad, la que puede prohibirlas sólo por motivos probados de seguridad o sanidad públicas.

\section{Artículo 5. Derechos políticos}

Los ciudadanos tienen derecho a participar en los asuntos públicos mediante referéndum, iniciativa de ley, revocación de autoridades y demanda de rendición de cuentas. También tienen derecho a ser elegidos y elegir libremente a sus representantes, de acuerdo con las condiciones y procedimientos determinados por Ley Orgánica.

Tienen derecho de votar los ciudadanos en goce de su capacidad civil. El voto es personal, igual, libre, secreto y obligatorio hasta los setenta años.

Es nulo y punible todo acto que prohíba o limite al ciudadano el ejercicio de sus derechos.

\section{Artículo 6. Materias de referéndum}

Pueden ser sometidas a referéndum:

1. La reforma total o parcial de la Constitución.

2. La aprobación de normas con rango de ley.

3. La voluntad de los pueblos de pertenecer a una u otra circunscripción territorial. $Y$

4. Las ordenanzas municipales en su respectiva jurisdicción. No pueden someterse a referéndum la supresión o disminución de derechos fundamentales de la persona ni normas de carácter tributario de alcance nacional ni tratados en vigor. 


\section{Artículo 7. Adquisición y pérdida de la ciu- dadanía}

Son ciudadanos los peruanos mayores de 18 años. Para el ejercicio de la ciudadanía se requiere la inscripción electoral.

El ejercicio de la ciudadanía se suspende:

1. Por resolución judicial de interdicción.

2. Por sentencia con pena privativa de libertad. $Y$

3. Por sentencia con inhabilitación de los derechos políticos.

\section{Artículo 8. Partidos políticos}

Los ciudadanos pueden ejercer sus derechos políticos en forma individual o asociada.

\section{Artículo 9. Deberes políticos}

Todos los peruanos tienen el deber de honrar al Perú, atender los intereses nacionales; y respetar los símbolos de la Patria.

Todos tienen el deber de cumplir la Constitución y de respetar el ordenamiento jurídico de la Nación.

El servicio militar es obligación patriótica. Se cumple en la forma y las condiciones, y con las excepciones que fija la ley.

\section{Del Estado y la Nación}

\section{Artículo 10. El Estado}

El Perú es una República democrática, independiente y soberana. El Estado es uno e indivisible. El gobierno es unitario, representativo y descentralizado. Se organiza según el principio de la separación e independencia de poderes.

Son símbolos de la Patria la bandera de franjas verticales con los colores rojo, blanco y rojo, el escudo y el himno nacional establecidos por ley.

La capital de la República del Perú es la ciudad de Lima.

El castellano es el idioma oficial de la República. En la forma que la ley establece, también tienen ese carácter el quechua, el aymara y otras lenguas nativas.
Artículo 11. Principios democráticos

La soberanía reside en el pueblo. El poder del Estado se ejerce por los funcionarios con las limitaciones y responsabilidades que establecen la Constitución y las leyes. Ninguna persona, organización, Fuerza Armada, Policía Nacional o sector del pueblo puede arrogarse su ejercicio. Hacerlo es rebelión.

Nadie debe obediencia a un gobierno usurpador ni a quienes asuman funciones en violación de la Constitución y las leyes. Son nulos los actos de los que usurpan funciones públicas.

Artículo 12. Jerarquía y publicidad de las normas jurídicas

La Constitución prevalece sobre toda norma legal. La ley, sobre las normas de inferior jerarquía, y así sucesivamente.

La publicidad es esencial para la vigencia de toda norma jurídica.

\section{Artículo 13. La nacionalidad}

Son peruanos por nacimiento los nacidos en el territorio de la República. También lo son los nacidos en el exterior de padre o madre peruanos inscritos en el registro correspondiente.

Son asimismo peruanos los que adquieren la nacionalidad por naturalización. La ley regula las formas en que se adquiere o recupera la nacionalidad.

La doble nacionalidad se rige por la ley y los tratados.

Nadie pierde la nacionalidad peruana, salvo renuncia expresa ante autoridad peruana.

\section{Artículo 14. El territorio}

El territorio del Estado es inalienable e inviolable. Comprende el suelo, el subsuelo, el dominio marítimo y el espacio aéreo que los cubre.

El dominio marítimo del Estado comprende el mar adyacente a sus costas, así como su lecho y subsuelo, hasta la distancia de dos- 
cientas millas marinas medidas desde las líneas de base que establece la ley.

El Estado ejerce soberanía en su dominio marítimo y en el correspondiente espacio aéreo que cubre su territorio y el mar adyacente sin perjuicio de las libertades de comunicación internacional, de conformidad con la ley y con los tratados.

El territorio de la República se distribuye en departamentos, provincias y distritos.

\section{Artículo 15. Los tratados}

Los tratados forman parte del derecho nacional. En caso de conflicto entre el tratado y la ley, prevalece el primero, bajo reserva de que el mismo principio sea aceptado por la otra $u$ otras partes contratantes.

Los tratados deben ser aprobados por el Congreso, antes de su ratificación por el Presidente de la República, si versan sobre derechos humanos, soberanía o integridad del Estado, defensa nacional, obligaciones financieras del Estado que creen, modifiquen o supriman tributos, y los que exigen modificación o derogatoria de alguna ley o requieran medidas legislativas para su ejecución.

La denuncia de los tratados es potestad del Presidente de la República, con cargode dar cuenta al Congreso.

\section{Artículo 16. Los tratados constitucionales}

Cuando el tratado afecte disposiciones constitucionales debe ser aprobado por el mismo procedimiento que rige la reforma de la Constitución, antes de ser ratificado por el Presidente de la República.

\section{De la Educación}

\section{Artículo 17. Régimen de la educación}

Las universidades y centros de educación inicial, primaria, secundaria y tecnológica, debidamente calificados como tales, gozan de inafectación de todo tributo directo. Gozan además de inafectación de todo tributo indirecto, solamente en el ejercicio de las actividades y servicios propios de la finalidad educativa y cultural.
Las referidas instituciones gozan, además, de los estímulos tributarios y de otra índoleque establecen las leyes para promover becas y donaciones en favor de las mismas. Están exoneradas de todo tributo que pueda gravar la constitución de las donaciones o becas.

La ley establece los requisitos que las mencionadas instituciones deben cumplir para acceder a la inafectación descrita y las condiciones requeridas por los demás centros educativos y culturales para gozar de alguna inafectación, así como los mecanismos que permitan los reintegros tributarios pertinentes que aseguren la adecuada fiscalización.

\section{De la Economía}

\section{Artículo 18. Marco de la intervención estatal}

La iniciativa privada es libre. Se ejerce en una economía de mercado. En ésta, el Estado cumple la función subsidiaria que le corresponde.

El Estado garantiza la libertad de empresa y de trabajo. Asimismo, defiende la libre competencia. Están prohibidos los controles de precio y todas aquellas regulaciones que perjudiquen la libertad económica de los individuos y de las personas jurídicas.

Los recursos naturales son patrimonio de la Nación. La ley fija las condiciones de su utilización y de su otorgamiento a los particulares. El Estado protege el ambiente. Dicta las leyes para prevenir la contaminación ambiental y el deterioro o la depredación de los recursos naturales y ecosistemas, así como las áreas protegidas.

Con el voto aprobatorio de dos tercios del Congreso, el Estado puede excepcionalmente realizar actividad empresarial por razón de manifiesta conveniencia nacional o alto interés público.

Los servicios públicos pueden ser prestados por empresas privadas según las leyes respectivas.

\section{Artículo 19. Inversión extranjera}

La inversión nacional y la extranjera se sujetan a las mismas condiciones y gozan de las mismas garantías. 
Artículo 20. Inviolabilidad de la propiedad

El derecho de propiedad es inviolable. A nadie puede privarse de la suya sino en caso indispensable y por causa de seguridad nacional o necesidad pública, declarada por ley y previo pago en efectivo de indemnización justipreciada. Hay acción ante el Poder Judicial para contestar el precio que el Estado haya señalado en el procedimiento expropiatorio.

En cuanto a la propiedad, los extranjeros están en la misma condición que los peruanos, sin que, en caso alguno, puedan invocar excepción ni protección diplomática.

El Estado garantiza la propiedad intelectual, incluyendo los derechos del autor y del inventor sobre sus respectivas obras y creaciones, de acuerdo a ley.

\section{Artículo 21. Características de la tributacióny del gasto público}

Todos tienen el deber de contribuir al sostenimiento del erario, de acuerdo con su capacidad económica, mediante un sistema tributario que se funda en los principios de reserva de la ley, igualdad, simplicidad y eficiencia. El sistema tributario no puede, en caso alguno, tener alcance confiscatorio.

La tributación se fija sólo de acuerdo a ley. No pueden establecerse privilegios personales, geográficos, sectoriales ni de ninguna otra clase.

Las obras y adquisiciones de suministros con utilización de fondos o recursos públicos se ejecutan por contrata y licitación, así como la adquisición o enajenación de bienes, en concordancia con la ley.

\section{Artículo 22. Ley de Presupuesto}

La administración económica y financiera del Estado se basa en los criterios de descentralización, equidad y eficiencia. Se rige por la Ley de Presupuesto. A más tardar el 28 de agosto de cada año, el Presidente de la República envía al Congreso el proyecto de Ley de Presupueto junto con los proyectos de ley de endeudamiento y equilibrio financiero.
El presupuesto de la República tiene dos secciones: una para el gobierno central; y otra, obligatoriamente, para las instancias descentralizadas.

El proyecto presupuestal debe estar verazmente equilibrado. Los ingresos provenientes del Banco de la Nación no se contabilizan como ingreso fiscal. Los préstamos del extranjero no se destinan a gastos corrientes. Necesariamente, debe existir una partida destinada al servicio de la deuda pública.

El pliego de ingresos del proyecto es sustentado en el Congreso por el Ministro de Economía y Finanzas. Cada ministro sustenta el respectivo pliego de egresos. El Presidente de la Corte Suprema sustenta el pliego del Poder Judicial.

Los representantes a Congreso no tienen iniciativa para crear ni aumentar gastos ni para reducir ingresos. Tienen iniciativa para reducir gastos y crear y aumentar ingresos, siempre que los mismos no tengan fines predeterminados. Tampoco pueden modificar la estimación del rendimiento de los ingresos consignados en el proyecto presupuestal.

\section{Artículo 23. Aprobación del Presupueto}

El Congreso debe aprobar la Ley de Presupuesto a más tardar el quince de diciembre de cada año. En caso con trario, el Ejecutivo queda autorizado para prorrogar por dozavos el presupuesto vigente.

Cualquier modificación a la Ley de Presupuesto debe tramitarse ante el Congreso.

\section{Artículo 24. Contraloría y Cuenta General}

La Contraloría General de la República es organismo técnico de derecho público que goza de autonomía de acuerdo a ley. Se encarga de supervisar la ejecución del Presupuesto de la República.

La Cuenta General de la República, acompañada del informe de auditoría de la Contraloría General, se remite por el Presidente de la República al Congreso a más tardar el 28 de julio del año siguiente al de ejecución del presupuesto. 


\section{Artículo 25. El Banco Central}

El Banco Central de Reserva del Perú es persona jurídica de derecho público. Su finalidad es preservar la estabilidad monetaria. Su carácter autónomo así como el alcance de sus funciones están determinados por su Ley Orgánica.

El Banco Central sólo realiza operaciones financieras. No puede establecer políticas discrecionales que constituyan discriminación contra personas jurídicas o naturales. Está expresamente prohibido el establecimiento de tipos de cambio diferenciados para el comercio exterior.

El Banco Central está prohibido de conceder financiamiento al erario, salvo en caso de guerra exterior o peligro de ella; pero está autorizado para comprar bonos del tesoro hasta el límite que señala la ley.

V

Del Estado

\section{Artículo 26. El Poder Legislativo}

El Poder Legislativo reside en el Congreso, el cual consta de Senado y de Cámara de Diputados. Los diputados son ciento dos. Los senadores son veintiuno. Los senadores se eligen en distrito nacional. Los diputados en distrito uninominal.

Todos los representantes tienen los mismos derechos y atribuciones.

\section{Artículo 27. Características del mando legislativo} cuatro años.

El Congreso se elige por un período de

Los candidatosa la presidencia no pueden integrar las listas de candidatos al Congreso. Los candidatos a vicepresidente pueden ser simultáneamente candidatos a representación parlamentaria.

El mandato legislativo es irrenunciable. Las sanciones disciplinarias que imponga el Congreso a los representantes y que impliquen suspensión de funciones no pueden exceder de ciento veinte días de legislatura.
Las vacantes que se producen en el Congreso se llenan con los candidatos suplentes en el orden en que aparecen en las listas respectivas, si fuere el caso. Cuando no hay accesitarios, el Presidente del Congreso convoca a elección complementaria.

\section{Artículo 28. Legislaturas}

El Congreso es convocado por el Presidente de la República en Legislatura Ordinaria dos veces al año. La primera legislatura comienza el 28 de julio y termina el 15 de diciembre. La segunda se abre el 1 de abril y termina el 31 de mayo.

El Congreso se reúne en legislatura extraordinaria a iniciativa del Presidente de la República o a solicitud de, por lo menos, dos tercios del número legal de representantes. En la convocatoria, se fijan la fecha de iniciación y la de clausura. Su duración no puede exceder de quince días. Las legislaturas extraordinarias tratan preferentemente los asuntos materia de la convocatoria.

El quórum para la instalación del Congreso en legislatura ordinaria o extraordinaria es de la mitad más uno del número de miembros en cada Cámara.

La instalación de la primera legislatura ordinaria se efectúa con asistencia del Presidente de la República. Ésta no es imprescindible para que el Congreso inaugure sus funciones.

El Presidente del Congreso conmina a concurrir a los representantes cuya inasistencia impide la instalación del Congreso. El requerimiento se hace por tres veces en el plazo de quince días. El tercer requerimiento se hace bajo apercibimiento de declararse la vacancia. Producida ésta, el Presidente del Congreso procede a llamar a los suplentes. $\mathrm{Si}$, dentro de los quince días siguientes, éstos tampoco acuden, convoca a elección complementaria. Los inasistentes no pueden postular a cargo o función pública en los diez años siguientes.

Artículo 29. Requisitos para ser representante

Para ser diputado se requiere ser peruano; gozar del derecho de sufragio; $y$ haber 
cumplido 25 años; $y$ haber cumplido 35 años para ser senador.

No pueden ser elegidos parlamentarios si no han dejado el cargo seis meses antes de la elección:

1. Los ministros y viceministros de Estado, el Contralor General, los prefectos y subprefectos.

2. Los miembros del Poder Judicial, del Ministerio Público y del Consejo Nacional de la Magistratura.

3. El Presidente del Banco Central de Reserva del Perú, el Superintendente de Banca y Seguros, el Superintendente de Administración Tributaria y el Superintendente de Aduanas. $Y$

4. Los miembros de las Fuerzas Armadas y de la Policía Nacional en actividad.

\section{Artículo 30. Incompatibilidades y prohibiciones}

El mandato parlamentario es incompatible con el ejercicio de cualquier otra función pública, excepto la de Ministro de Estado y el desempeño, previa autorización del Congreso, decomisiones extraordinarias de carácter internacional.

Es asimismo incompatible con la condición de gerente, apoderado, representante, mandatario, abogado, accionista mayoritario, director de empresas que tienen contratos de obras, suministros o aprovisionamiento con el Estado o que administren rentas o presten servicios públicos, así como de empresas que obtengan concesiones del Estado.

Los parlamentarios están prohibidos de trabajar en cualquier banco estatal o asociado, o en cualquier empresa pública o de economía mixta.

Están prohibidos de ejercer representación, asesoría o defensa ante institución alguna ni ante el Poder Judicial, salvo en causa propia, de su cónyuge o de sus parientes hasta el cuarto grado de consanguinidad y segundo de afinidad.

\section{Artículo 31. Garantías del mandato legislativo}

Los parlamentarios representan a la Nación. No están sujetos a mandato imperativo ni a interpelación. No son responsables ante autoridad ni tribunal algunos por las opiniones y votos que emiten en el ejercicio de sus funciones.

No pueden ser procesados ni presos, sin previa autorización de su Cámara desde que son elegidos hasta un mes después de haber cesado en sus funciones, excepto por delito flagrante, caso en el cual son puestos a disposición del Congreso dentro de las veinticuatro horas siguientes, a fin de que se autoricen o no la privación de la libertad y el enjuiciamiento.

\section{Artculo 32. Funcionamiento del Congreso}

El Congreso y las Cámaras elaboran y aprueban su Reglamento; establecen la organización y las atribuciones de los grupos parlamentarios; arreglan su economía; sancionan su presupuesto; nombran y remueven a sus funcionarios y empleados; y les otorgan los beneficios que les corresponden, de acuerdo a ley.

Las sesiones plenarias del Congreso y de las Cámaras son públicas, salvo los casos que señala el Reglamento.

\section{Artículo 33. Atribuciones del Congreso}

Son atribuciones del Congreso:

1. Dar leyes y resoluciones legislativas así como interpretar, modificar o derogar las existencias.

2. Velar por el respeto de la Constitución y de las leyes, y disponer lo conveniente para hacer efectiva la responsabilidad de los infractores.

3. Aprobar los tratados de conformidad con la Constitución.

4. Aprobar el Presupuesto y la Cuenta General.

5. Autorizar empréstitos.

6. Ejercer el derecho de amnistía.

7. Aprobar la demarcación territorial que proponga el Poder Ejecutivo. $Y$

8. Ejercer las demás atribuciones que le señala la Constitución y las que son propias de la función legislativa.

\section{Artículo 34. Principios legislativos}

Pueden expedirse leyes especiales porque lo exige la naturaleza de las cosas, pero no 
por la diferencia de las personas. Las leyes obligan por igual a todos los habitantes de la República. troactivos.

Ninguna ley tiene fuerza ni efecto re-

Una ley sólo se deroga mediante otra ley.

\section{Artículo 35. Delegación de facultades}

El Congreso puede delegar en el Poder Ejecutivo la facultad de legislar, mediante decretos legislativos, sobre la materia y por el término que especifica la ley autoritativa.

Los decretos legislativos están sometidos, en cuanto a su promulgación, publicación, vigencia y efectos, a las mismas normas que rigen para la ley.

\section{Artículo 36. Formación de las leyes}

Tienen derecho de iniciativa, en la formación de las leyes, el Presidente de la República y los senadores y diputados.

Los proyectos enviados por el Poder Ejecutivo, con carácter de urgentes, tienen preferencia del Congreso.

También lo tienen, en las materias que le son propias, los proyectos de la Corte Suprema, el Ministerio Público, el Jurado Nacional de Elecciones, las municipalidades provinciales, así como los ciudadanos que ejerzan el derecho de iniciativa conforme a la ley de la materia.

Todo proyecto de ley se inicia en la Cámara de Diputados. El Senado lo revisa. Con el voto de los dos tercios de sus miembros, la Cámara de Diputados puede -después de sesenta días- prescindir de la ratificación del Senado o rechazar, en todo o en parte, las modificaciones que éste haya introducido.

\section{Artículo 37. Promulgación de las leyes}

La ley aprobada por el Congreso se envía al Presidente de la República, para que la promulgue en el término de quince días. En caso contrario, lo hace el Presidente del Congreso.
Si el Presidente de la República tiene observaciones que hacer, en todo o en parte, respecto de la ley aprobada en el Congreso, las presenta a éste en el mencionado término de quince días.

Reconsiderada la ley en el Congreso, el Presidente de éste la promulga, siempre que, en contra de cada una de las observaciones del Presidente de la República, voten más de la mitad del número legal de los representantes al Congreso en cada Cámara.

La ley es obligatoria desde el día siguiente de su publicación en el diario oficial, salvo disposición contraria de la misma ley para postergar su vigencia en todo o en parte.

\section{Artículo 38. El Presidente de la República}

El Presidente de la República es el Jefe del Estado y personifica a la Nación.

Para ser elegido Presidente de la República, se requiere ser peruano por nacimiento, gozar del derecho de sufragio y tener más de treinta y cinco años de edad al tiempo de la postulación.

\section{Artículo 39. Elección y juramento del Presidente}

El Presidente de la República es elegido por sufragio directo, y por más de la mitad de los votos. Los votos viciados o en blanco no se consideran para este efecto.

Si ninguno de los candidatos obtiene la mayoría absoluta, se procede a segunda elección dentro de los treinta días siguientes de proclamados los cómputos oficiales entre los candidatos que han obtenido las dos más altas mayorías relativas.

Junto con el Presidente de la República, son elegidos, de la misma manera, con los mismos requisitos y por igual término, dos vicepresidentes.

El mandato presidencial es de cuatro años. El Presidente no puede ser reelegido sino después de que haya transcurrido, por lo menos, un período constitucional.

El Presidente presta juramento y asume el cargo ante el Congreso el 28 de julio del año en que se realiza la elección. 
Artículo 40. Vacancia de la presidencia de la República

La presidencia de la República vaca, además del caso de muerte, por:

1. Permanente incapacidad física o moral declarada por el Congreso.

2. Aceptación de la renuncia por el Congreso.

3. Salir del territorio nacional sin permiso del Congreso o no reincorporarse al vencimiento de éste. $Y$

4. Destitución, al haber sido sancionado por alguna de las infracciones que contempla el artículo 43 de la Constitución.

\section{Artículo 41. Suspensión de la presidencia de la República}

El ejercicio de la presidencia de la $\mathrm{Re}$ pública se suspende por:

1. Incapacidad temporal declarada por el Congreso. $\mathrm{O}$

2. Hallarse sometido a juicio, conforme al artículo 43 de la Constitución.

\section{Artículo 42. Reemplazo del Presidente de la República}

Por falta temporal o permanente del Presidente de la República, asume sus funciones el primer Vicepresidente. En defecto de éste, el segundo Vicepresidente. Por impedimento de ambos, el Presidente del Congreso, quien convoca de inmediato a elecciones si el impedimento es permanente.

Cuando el Presidente sale del territorio nacional, el primer Vicepresidente se encarga del despacho. En su defecto, el segundo Vicepresidente.

Artículo 43. Acusación del Presidente de la República

El Presidente de la República sólo pue de ser acusado por traición a la patria; por impedir las elecciones presidenciales, parlamentarias o municipales; por disolver el Congreso; y por impedir su reunión o funcionamiento, o los del Jurado Nacional de Elecciones.

Artículo 44. Facultades del Presidente de la República

Correspondeal Presidente de la República:

1. Cumplir y hacer cumplir la Constitución y los tratados, leyes y demás disposiciones legales.

2. Representar al Estado, dentro y fuera de la República.

3. Velar por el orden interno y la seguridad exterior de la República.

4. Convocar a elecciones para Presidente de la República y para representantes a Congreso, así como para alcaldes y regidores y demás funcionarios que señala la ley.

5. Convocar al Congreso a legislatura extraordinaria.

6. Dirigir mensajes al Congreso en cualquier época y, obligatoriamente, en forma personal y leyéndolo, al instalarse la primera legislatura ordinaria anual. Los mensajes del Presidente de la República, salvo el primero, son aprobados por el Consejo de Ministros.

7. Ejercer la potestad de reglamentar las leyes sin trasgredirlas ni desnaturalizarlas; $y$, dentro de tales límites, dictar decretos y resoluciones.

8. Cumplir y hacer cumplir las sentencias y resoluciones de los tribunales y juzgados, así como las del Jurado Nacional de Elecciones.

9. Dirigir la política exterior y las relaciones internacionales, y celebrar y ratificar tratados.

10. Nombrar embajadores y ministros plenipotenciarios, con aprobación del Consejo de Ministros y con cargo de dar cuenta al Congreso.

11. Recibir a los agentes diplomáticos extranjeros, y autorizar a los cónsules el ejercicio de sus funciones.

12. Disponer de las Fuerzas Armadas y la Policía Nacional.

13. Declarar la guerra y firmar la paz, con autorización del Congreso. 
14. Administrar la hacienda pública y negociar los empréstitos.

15. Dictar medidas extraordinarias, mediante decretos de urgencia con fuerza de ley, en materia económica y financiera, cuando así lo requiere el interés nacional y con cargo de dar cuenta al Congreso. El Congreso puede modificar oderogar tales decretosdeurgencia.

16. Regular las tarifas arancelarias.

17. Conceder indultos y conmutar penas.

18. Conferir condecoraciones a nombre de la Nación, con acuerdo del Consejo de Ministros.

19. Autorizar a los peruanos para servir en ejército extranjero. $Y$

20. Ejercer las demás funciones de gobierno que las leyes le encomiendan.

\section{Artículo 45. El Consejo de Ministros}

La dirección y la gestión de los servicios públicos están confiados al Consejo de Ministros, y a los ministros en los asuntos que competen al ministerio de su cargo.

Son nulos los actos del Presidente de la República que no tienen refrendación ministerial.

La ley determina el número de ministerios, sus denominaciones y las reparticiones de cada uno.

Los ministros, reunidos, forman el Consejo de Ministros. La ley determina su organización y funcionamiento.

El Consejo de Ministros tiene su Presidente. Corresponde al Presidente de la República presidir el Consejo de Ministros cuando lo convoca o asiste a sus sesiones.

El Presidente de la República nombra y remueve al Presidente del Consejo. Nombra y remueve a los demás ministros, a propuesta y con acuerdo, respectivamente, del Presidente del Consejo.

Los ministros deben ser peruanos, ciudadanos en ejercicio y haber cumplido los veinticinco años de edad.

\section{Artículo 46. El Presidente del Consejo}

Al Presidente del Consejo de Ministros, quien puede ser ministro sin cartera, le corresponde:
1. Ser, después del Presidente de la República, el portavoz autorizado del gobierno.

2. Coordinar las funciones de los demás ministros. $Y$

3. Refrendar los decretos legislativos, los decretos de urgencia y los demás decretos y resoluciones que señalan la Constitución y la ley.

\section{Artículo 47. Responsabilidad de los ministros}

Cada uno de los ministros es responsable individualmente por sus propios actos y por los actos presidenciales que refrende. Todos los ministros son solidariamente responsables por los actos delictivos o infractorios de la Constitución o de las leyes en que incurra el Presidente de la República o que se acuerden en Consejo, aunque salven su voto, a no ser que renuncien inmediatamente.

\section{Artículo 48. Asistencia de los ministros al Congreso}

El Consejo de Ministros en pleno o los ministros separadamente pueden concurrir a las sesiones del Congreso y participar en sus debates con las mismas prerrogativas que los parlamentarios, salvo la de votar. Si el ministro es parlamentario, tiene derecho a voto.

Los ministros concurren también al Congreso cuando son invitados para informar.

El Presidente del Consejo, o por lo menos uno de los ministros, concurre a las sesiones plenarias del Congreso para la estación de preguntas.

\section{Artículo 49. Investidura del Consejo de Ministros}

Dentro de los treinta días de haber asumido sus funciones, el Presidente del Consejo concurre al Congreso, en compañía de los demás ministros, para exponer y debatir la política general del gobierno y las principales medidas que requiere su gestión.

Plantea para el efecto la cuestión de confianza. 
Si el Congreso no está reunido, el Presidente de la República convoca a legislatura extraordinaria.

\section{Artículo 50. Interpelación y censura de ministros}

Es obligatoria la concurrencia del Consejo de ministros o de cualquiera de los ministros cuando la Cámara de Diputados los llama para interpelarlos.

La interpelación se formula por escrito. Debe ser presentada por no menos del quince por ciento del número legal de diputados. Para su admisión, se requiere el voto del tercio por lo menos del número de diputados hábiles; y dicho voto se efectúa a más tardar en la sesión siguiente.

La Cámara de Diputados hace efectiva la responsabilidad política del Consejo de $\mathrm{Mi}$ nistros, o de los ministros por separado, mediante el voto de censura o el rechazo de la cuestión de confianza. Esta última sólo se produce por iniciativa ministerial.

Toda moción de censura contra el Consejo de Ministros o cualquiera de los ministros debe ser presentada por no menos de un tercio del número legal de diputados. Se debate y vota entre el cuarto y el décimo día natural de su presentación.

Su aprobación requiere el voto conforme de más de la mital del número legal de miembros de la Cámara de Diputados.

El Consejo de Ministros o el ministro censurado debe renunciar. dimisión.

El Presidente de la República acepta la

El Senado no interpela ni censura a los ministros; pero los puede invitar.

\section{Artículo 51. Renovación del Congreso}

Cada dos años, se renuevan por mitades el Senado y la Cámara de Diputados.

\section{Artículo 52. Régimen de excepción}

El Presidente de la República, con acuerdo del Consejo de Ministros, puede decre- tar, por plazo determinado, en todo o en parte del territorio y dando cuenta al Congreso o a la Comisión Permanente, los estados de excepción que en este artículo se contemplan:

1. Estado de emergencia, en caso de perturbación de la paz o del orden interno, de catástrofe o de graves circunstancias que afecten la vida de la Nación. En esta eventualidad, puede suspender las garantías constitucionales relativas a la seguridad jurídica, a la inviolabilidad del domicilio, a la libertad de movimiento, a la libertad de reunión y a la seguridad y libertad personales contempladas en el artículo 3, inciso 7, y en el artículo 4. En ninguna circunstancia se puede desterrar a nadie. El plazo del estado de emergencia no excede de sesenta días. La prórroga requiere nuevo decreto. En estado de emergencia, las Fuerzas Armadas asumen el control del orden interno cuando así lo dispone el Presidente de la República. $Y$

2. Estado de sitio, en caso de invasión, guerra exterior, guerra civil o peligro inminente de que se produzcan, con especificación de las garantías personales que continúan en vigor. El plazo correspondiente no excede de cuarenta y cinco días. Al decretarse el estado de sitio, el Congreso se reúne de pleno derecho. La prórroga requiere aprobación del Congreso.

\section{Artículo 53. E1 Poder Judicial}

La potestad de administrar justicia se ejerce por el Poder Judicial a través de sus órganos jerárquicos con arreglo a la Constitución y a las leyes. Toda persona tiene derecho a la tutela jurisdiccional.

\section{Artículo 54. Principios de la función} jurisdiccional

Son principios de la función jurisdiccional y derechos en el proceso:

1. La unidad y la exclusividad de la función jurisdiccional. No existe jurisdicción alguna independiente, con excepción de la militar. 
2. La independencia en su ejercicio. Ninguna autoridad puede abocarse a causas pendientes ante el órgano juridiccional ni interferir el ejercicio de sus funciones. La investigación parlamentaria no puede duplicar la investigación judicial. Tampocos se pueden dejar sin efecto resoluciones que han pasado en autoridad de cosa juzgada ni cortar procedimientos en trámite ni modificar sentencias ni retardar su ejecución. Esta disposición no afecta el derecho de gracia.

3. La observancia del proceso debido. Ninguna persona puede ser desviada de la jurisdicción predeterminada por la ley ni sometida a procedimientos distintos de los previamente establecidos.

4. La publicidad de los procesos, salvo disposición en contrario de la ley. Los juicios por responsabilidad de funcionarios públicos, delitos de prensa y los que se refieren a derechos fundamentales garantizados por la Constitución, siempre son públicos.

5. La motivación escrita de las resoluciones judiciales en todas las instancias, excepto los decretos de mero trámite, con mención expresa de la ley aplicable y de los fundamentos de hecho en que se sustentan.

6. La pluralidad de la instancia.

7. La indemnización, en la forma que determine la ley, por los errores judiciales en los procesos penales y por las detenciones arbitrarias, sin perjuicio de la responsabilidad a que hubiera lugar.

8. La prohibición de ejercer función judicial por quien no ha sido nombrado en la forma prevista por la Constitución o la ley. Y

9. El derecho de los internos y sentenciados de ocupar establecimientos sanos y convenientes.

\section{Artículo 55. Pena de muerte}

La pena de muerte sólo puede aplicarse por los delitos de traición a la Patria, de terrorismo y por los crímenes atroces, conforme a las leyes internas y a los tratados de los que es parte el Perú.

\section{Artículo 56. El Consejo Nacional de la} Magistratura

El Consejo Nacional de la Magistratura y los Consejos Distritales se encargan de la selección, el nombramiento y el ascenso de los jueces. El Senado ratifica los nombramientos.

El Consejo de la Magistratura es independiente y se rige por su Ley Orgánica.

La máxima instancia del Consejo Nacional de la Magistratura es el tribunal de honor, cuyos miembros lo son a título vitalicio. Producida una vacante la provee dicho Tribunal.

\section{Artículo 57. El Ministerio Público}

El Ministerio Público es autónomo. Lo preside el Fiscal de la Nación, quien es elegido por el Consejo Nacional de la Magistratura con el voto de los dos tercios del número legal de sus miembros. El cargo de Fiscal de la Nación dura tres años, prorrogables tres años más por reelección. Orgánica.

El Ministerio Público se rige por su Ley

El Defensor del Pueblo ejecuta los derechos y goza de las prerrogativas que una ley orgánica le confiere.

\section{Artículo 58. Las Fuerzas Armadas y la Policía Nacional}

Las Fuerzas Armadas están constituidas por el Ejército, la Marina de Guerra y la Fuerza Aérea. Tienen como finalidad primordial garantizar la integridad territorial de la República. Asumen el control del orden interno de conformidad con el artículo 52 de la Constitución.

La Policía Nacional tiene por finalidad fundamental garantizar, mantener y restablecer el orden interno. Debe prestar protección y ayuda a las personas y a la comunidad. Garantiza el cumplimien to de las leyes y la seguridad de los patrimonios públicos y privados. Previene y combate la delincuencia. Vigila y controla las fronteras. 
El Presidente de la República es el Jefe Supremo de las Fuerzas Armadas y la Policía Nacional, las cuales no son deliberantes sino obedientes al poder constitucional. Los miembros de las Fuerzas Armadas y de la Policía Nacional en actividad no pueden elegir ni ser elegidos. Son ciudadanos que tienen en suspenso el derecho de sufragio. Pueden ser ministros.

\section{Artículo 59. El sistema electoral}

El sistema electoral está dirigido por el Jurado Nacional de Elecciones, que se conforma de la siguiente manera:

1. Un representante de la Corte Suprema, quien lo preside, elegido por votación secreta entre los magistrados jubilados en los últimos tres años.

2. Un representante del Colegio de Abogados de Lima, elegido entre sus miembros por votación secreta.

3. Un representante de los demás colegios de abogados del Perú, elegido entre los decanos y en votación secreta.

4. Un representante de los otros colegios profesionales de nivel nacional, elegido por votación secreta de los decanos de los mismos. Y

5. Un representante de la Asamblea Nacional de Rectores elegido entre los exrectores en votación secreta.

\section{Artículo 60. Garantías constitucionales}

La Sala Constitucional es el órgano de control de la Constitución y forma parte de la Corte Suprema. Tiene potestad para:

1. Conocer, en instancia única, la acción de inconstitucionalidad. $Y$

2. Conocer, en segunda y definitiva instancia, las acciones de habeas corpus, amparo y acción popular.

Las acciones a las que se refiere el presente artículo, así como su procedimiento, se rigen por la respectiva Ley Orgánica.

\section{De la Descentralización}

\section{Artículo 61. Principio fundamental de la descentralización}

Todo poder que no esté delegado por esta Constitución al gobierno central, ni prohibido por ella a los gobiernos municipales o a los gobiernos regionales, corresponde a éstos o al pueblo.

\section{Artículo 62. Gobiernos municipales}

Los Alcaldes y regidores de los Concejos Municipales son elegidos en sufragio directo; por los vecinos de su respectiva jurisdicción, por un período de cuatro años. También son elegidos por sufragio directo el Gobernador y el Teniente Gobernador de los gobiernos regionales.

Los Alcaldes y Regidores de los Concejos Municipales pueden ser reelegidos indefinidamente.

Los gobiernos regionales se establecen en uno o más departamentos, de acuerdo con la voluntad que el pueblo expresa en referéndum, y conforme a ley.

\section{Artículo 63. Financiamiento municipal}

Son rentas de los Concejos Municipales los recursos que resulten de su participación en los impuestos nacionales, en las proporciones que determine la ley y que debe consignar la Ley Anual de Presupuesto.

Los gobiernos regionales y las municipalidades son autónomos. Los Concejos Municipales pueden fijar las tasas de los tributos que les corresponden de acuerdo a ley, para financiar los servicios públicos que prestan dentro de su jurisdicción. Esta facultad debe sujetarse a lo dispuesto en la ley marco de la materia.

\section{Artículo 64. Concejos Regionales}

Los Concejos Municipales pueden asociarse para el mejor cumplimiento de sus fines. 
Los Concejos Regionales se encargan de la coordinación de las actividades de desarrollo denivel interprovincial y de la resolución de conflictos en la vía administrativa entre los municipios de su circunscripción.

\section{Reforma de la Constitución}

\section{Artículo 65. Reforma de la Constitución}

Toda reforma constitucional debe ser aprobada en una legislatura ordinaria y ratificada en otra legislatura ordinaria. La ley respectiva no es suceptible de observación por el Poder Ejecutivo.

La aprobación y la ratificación requieren la mayoría absoluta de los votos del número legal de miembros del Congreso.

La iniciativa corresponde al Presidente de la República, con aprobación del Consejo de Ministros; a los representantes; a la Corte Suprema en materia judicial con acuerdo de Sala Plena; y a mil ciudadanos con firmas verificadas por el Jurado Nacional de Elecciones.

\section{Disposiciones Finales y Transitorias}

Primera. Elecciones generales

Las elecciones generales establecidas por la presente Constitución se efectúan en 1995. El Presidente electo asume sus funciones el 28 de julio de ese año.

Segunda. De la configuración de los ámbitos regionales provinciales y distritales

Inicialmente, los ámbitos regionales están constituidos por cada uno de los veinticuatro departamenteos siguientes: Arequipa, Amazonas, Ancash, Apurímac, Ayacucho, Cajamarca, Cuzco, Huánuco, Huancavelica, Ica, Junín, La Libertad, Lambayeque, Lima -salvo su provincia capital y la Provincia Constitucional del Callao que, por separado, tienen régimen especial en la Ley Orgánica de descentralización- Loreto, Madre de Dios, Moquegua, Pasco, Piura, Puno, Tacna, Tumbes, San Martín y Ucayali. En ningún caso se incre- mentará el número de regiones señalado. Dos o más regiones colindantes pueden fusionarse en una sola mediante referéndum. Igualmente las provincias y distritos colindantes pueden fusionarse o cambiar de circunscripción mediante referéndum de acuerdo a procedimiento y plazos que la ley señale.

Tercera. De las Municipalidades Distritales del Cercado

Créanse las Municipalidades Distritales del Cercado en todas las provincias de la República, eligiéndose a sus respectivos alcaldes y regidores en las próximas elecciones municipales.

Cuarta.

Elecciones parlamentarias $y$ municipales

Para 1995 los representantes a Congreso se eligen la mitad por cuatro años, y la otra mitad por seis, de modo que se cumpla cada dos años la renovación por mitades. En adelante, los senadores y los diputados se renuevan al vencimiento de su período de cuatro años.

Las elecciones municipales establecidas por la presente Constitución se realizan en 1997. Los Concejos Municipales electos deben asumir sus funciones el 28 de julio de ese año.

Los actuales Concejos Municipales quedan prorrogados en sus mandatos hasta que asumen sus funciones los nuevos Concejos Municipales.

Las elecciones municipales y de una mitad del Congreso se intercalan cada dos años con las elecciones de Presidente de la República y de la otra mitad del Congreso.

\section{Quinta. Vigencia}

La presente Constitución, una vez que entre en vigor, sustituye a la Constitución de 1979.

Sexta. Del referéndum

Después de su aprobación por el Congreso Constituyente democrático, y antes de su 
promulgación por el Presidente de la República, se consulta al pueblo la presente Constitución para que conteste por un sí o por un no a las preguntas siguientes:

1. Si está de acuerdo con el régimen bicameral.

2. Si está de acuerdo con la reelección del Presidente, sólo después de transcurrido un período constitucional.

3. Si está de acuerdo con la pena de muerte en los términos que contempla la presente Constitución. $Y$
4. Si está de acuerdo con que los gobiernos regionales, inicialmente, queden o no constituidos por cada departamento.

El CCD procede a las correcciones a que hubiere lugar, según los resultados del referéndum. Terminado este proceso, si fuere el caso, el CCD procede a aprobar el texto final de la Constitución, y el Presidente de la República la promulga. 